\title{
OPEN Seismic signature of the deadly snow avalanche of January 18, 2017, at Rigopiano (Italy)
}

\author{
Thomas Braun ${ }^{1 凶}$, Barbara Frigo $\mathbb{D}^{2}$, Bernardino Chiaia $\mathbb{D}^{2}$, Perry Bartelt ${ }^{3}$, \\ Daniela Famiani ${ }^{1}{ }^{1}$ \& Joachim Wassermann $\mathbb{D}^{4}$
}

Most snow avalanches occur unobserved, which becomes particularly dramatic when human lives are involved. Seismological observations can be helpful to unravel time and dynamics of unseen events, like the deadly avalanche of January 18, 2017, that hit a Resort-hotel at Rigopiano in the Abruzzi (Italy). Particle motion analysis and spectrograms from data recorded by a close seismic broadband station, calculation of synthetic seismograms, as well as simulation of the flow, allowed us to construct the dynamics of the snow avalanche that buried alive 40 people, killing 29. Due to the bad weather conditions, no visual observation was made, thus making it impossible to determine the exact moment of the avalanche and to report necessary observations of the dramatic event. On-site inspections revealed that the hotel was horizontally cut by shear forces and dislocated by $48 \mathrm{~m}$ in $70^{\circ} \mathrm{N}$ direction, once the increasing avalanche pressure exceeded the structural shear strength of the building. Within an eligible $24 \mathrm{~min}$ time range of the avalanche, we found three weak seismic transients, starting at 15:42:38 UTC, recorded by the nearest operating station GIGS located in the Gran Sasso underground laboratory approximately $17 \mathrm{~km}$ away. Particle motion analysis of the strongest seismic avalanche signal, as well as of the synthetic seismograms match best when assuming a single force seismic source, attacking in direction of $120^{\circ} \mathrm{N}$. Simulation of the avalanche dynamics - calculated by using a 2D rapid mass movement simulator-indicates that the seismic signals were rather generated as the avalanche flowed through a narrow and twisting canyon directly above the hotel. Once the avalanche enters the canyon it is travelling at maximum velocity $(37 \mathrm{~m} / \mathrm{s})$ and is twice strongly deflected by the rock sidewalls. These impacts created a distinct linearly polarized seismic "avalanche transient"s that can be used to time the destruction of the hotel. Our results demonstrate that seismic recordings combined with simulations of mass movements are indispensable to remotely monitor snow avalanches.

Seismology provides useful tools that can help to better understand the dynamics of seismic events, different from earthquakes, as e.g. volcanic eruptions, rock falls or huge landslides ${ }^{1-5}$. There are only a few examples in literature where seismology was successfully used to study avalanches ${ }^{6-10}$, probably because the density of snow is up to ten times smaller, compared to debris, which results in a reduced ground coupling and in a smaller seismic signal amplitude. On January 18, 2017, in a remote location in the Abruzzo region (Central Italy), a deadly avalanche buried 40 people under the Resort-hotel "Rigopiano". In a dramatic rescue operation 11 people could be recovered, while for another 29 persons there was no way to escape. The bad weather conditions with heavy snowfall closed the access road, isolating the Rigopiano location from the outside world. The reduced visibility prevented any eyewitness report of the avalanche, thus the exact moment, as well as the dynamics of this catastrophic event, are still not confirmed. We use seismic recordings and on-site inspection, combined with numerical modelling, to reconstruct the dynamics and to determine the exact moment of the deadly avalanche.

Chronology. A brief cold period lasting from January 15 to 19,2017 , caused abundant snowfall in the Marche and Abruzzo regions, reaching a snow depth of about $2 \mathrm{~m}$ at altitudes above $1000 \mathrm{~m}$.a.s.l. in the Sibillini and Gran Sasso mountains. In the morning of January 21, 2017, and thus three days after the avalanche, the

\footnotetext{
${ }^{1}$ Istituto Nazionale di Geofisica e Vulcanologia, Roma, Italy. ${ }^{2}$ Department of Structural, Building and Geotechnical Engineering, Politecnico di Torino, Torino, Italy. ${ }^{3} \mathrm{WSL}$ Institute for Snow and Avalanche Research SLF, Davos, Switzerland. ${ }^{4}$ Geophysical Observatory, Munich University, Fürstenfeldbruck, Germany. ${ }^{\circledR}$ email: thomas.braun@ ingv.it
} 
Meteo-service agency ${ }^{11}$ estimated a fresh snow depth of $2 \mathrm{~m}$ near hotel Rigopiano in the location of Farindola (1200 m.a.s.l., Pescara Province), and even more on top of Mt. Siella (2027 m.a.s.l., Fig. 1).

On January 18,2017, between 09:25 and 13:33 UTC four seismic events of magnitude $M \geq 5$ occurred at a distance of circa $45 \mathrm{~km}$ W off the location of hotel Rigopiano (yellow stars in Fig. 1a) causing tremors perceptible as far as Rome and Naples. As those earthquakes were distinctly felt also at Rigopiano, spreading panic among the hotel residents, the question arose, whether the avalanche could have been seismically triggered ${ }^{12}$. Given the large epicentral distance and a minimum $2 \mathrm{~h}$ time offset between the latest M5 event and the snow mass detachment, we consider it as very unlikely that the avalanche was released by ground oscillations from those events, while temperature increase in the course of the day may, however, play an important role for triggering the avalanche.

Due to the bad weather conditions, fresh snow interrupted the $9 \mathrm{~km}$ long access road to the hotel, cutting also power and telecommunication lines. Therefore, none of the entrapped 11 employees and 29 guests had any chance, neither to receive help from the outside, nor to leave the hotel. In the afternoon of January 18, 2017, almost two hours after the last M5.0 earthquake of 13:33 UTC (all times are indicated as UTC = local time $-1 \mathrm{~h}$ ), a snow avalanche detached from Mt. Siella at 1969 m.a.s.l., increasing its mass, while running down the $2 \mathrm{~km}$ long wooded valley heading for Rigopiano. The power of its masses buried the Resort hotel with 40 residents and swept away the entire upper floors comprising the roof.

There are only two indirect eyewitnesses of this deadly event: One is the hotel maintenance technician (F.S.), who experienced the avalanche inside the hotel's heating room, a small technical compartment, which was indeed concerned by entering snow, but did not collapse. F.S. freed himself, after approximately 15 min; he later reported: "the avalanche was silent [...]. No roar, no air movement. A loud rustling"14. The second eyewitness is the hotel guest (G.P.) who, shortly before the avalanche, went outside to the parking area to pick up something in his car. On his way back to the hotel, he heard noises and squeaks and was partially submerged by the snow. Later, he said: "I saw the mountain falling on the hotel"15. It was G.P. who transmitted the first emergency call at 16:40 UTC. Any earlier attempt to call for help was unsuccessful due to the intermittent mobile phone connection, leaving unanswered the question about the exact moment of the avalanche.

To define an accurate timing of the avalanche is of great importance for the victims' relatives, as well as for issues regarding the rescue operations. The last phone call from hotel Rigopiano before the avalanche was taken at 15:30, and as reported by $\mathrm{BBC}^{16}$, the avalanche struck sometime before $16: 40$, when the first emergency call was received. As reported by the newspaper "La Repubblica"17, subsequent inspections of the victims' mobile phones revealed that on 16:09 one of the guests sent an audio WhatsApp Message (WAM) to the sanitary emergency of the Province capital Chieti, with the words: "Hotel Rigopiano, collapse, avalanche, survivors, missing". This information shortens the time window of the possible avalanche from 70 to $39 \mathrm{~min}$. A further WAM "Help, I'm blocked by the rubble", written at 15:54 but never sent, restricts the avalanche time window to 24 min, starting at $15: 30$.

Avalanche parameters retrieved from on-site inspections. The track and the trajectory of the Rigopiano avalanche are easy to identify from on-site observations. The rapid flow of avalanches hits a corridor in the beech forest, carving parabolic curves, and impacts the hotel by spreading branches of trees, cars, lanterns, boulders and roots. Several on-site inspections revealed that, from a dynamic point of view, the event of January 18,2017 , could be classified as "mixed" avalanche, i.e. the combination of a skimming flow and a powder part. Moreover, the dry snow of medium-high density with weak internal friction and high velocities led to a predominantly deforesting action. As tree breaking extracts little kinetic energy from the avalanche ${ }^{18,19}$, the forest did not decelerate the avalanche significantly. Large parts of the forest were thus entrained and transformed the avalanche in a sort of fast landslide of snow and wood, steamrolling the fragile parts of the forest and dragging the trunks. The avalanche increased its already high kinetic energy travelling the entire slope, building up its mass and varying its density caused by the entrainment of the fresh snowpack, rocks and the uprooted beech forest. The avalanche impacted the hotel by burst of compacted snow mixed with wood, dirt, rocks and boulders, growing the overall impact pressure of flow on the Hotel. The high kinetic energy of the avalanche due to its elevated density-from the entrainment of wood and trunks - resulted in an increased impact velocity when striking the hotel, dislocating the upper part (Fig. 1b). The Rigopiano event can be defined as a "wood-and-snow" avalanche: the fast snow flow broke the beeches already at the beginning of the sliding zone, crossing a rocky spur (usually bypassed by avalanches) and rising its destructiveness without any deceleration effect. At the run-out zone, the snow and wood deposits about $4 \mathrm{~m}$ thick were measured over a distance of nearly $450 \mathrm{~m}$ downstream from the hotel, where the slope of this grassy plateau does not exceed $4^{\circ}$ (against horizontal). The total distance travelled by the dense avalanche reaches $2.3 \mathrm{~km}$. The front of the avalanche instantly overwhelmed the hotel, destroyed the masonry walls, broke the reinforced concrete columns and made the beams/columns connections collapse, thus weakening the bearing structure.

The mass of snow and debris shifted the upper floors of the hotel by approximately $48 \mathrm{~m}$ downstream, rotated them slightly by $13^{\circ}$ anticlockwise (Fig. 1b), teared them apart and entered the lower and underground floors of the hotel. This westernmost portion of the building constructed at the end of the 1960s along the upstream side was facing the frontal impact of the flow, with an angle of incidence approximately orthogonal (less than $\pm 20^{\circ}$ with respect to the perpendicular) and (minimum) height of the second floor above ground.

According to the local topography, the upstream part of the hotel building resides in a recessed position with respect to the ground level covered by $3 \mathrm{~m}$ thick snowpack, protecting in this way the lower floors of the building against the approaching avalanche. The mass flow was thus deviated directly to the second floor, which collapsed subsequently by shearing, without affecting the foundation. 

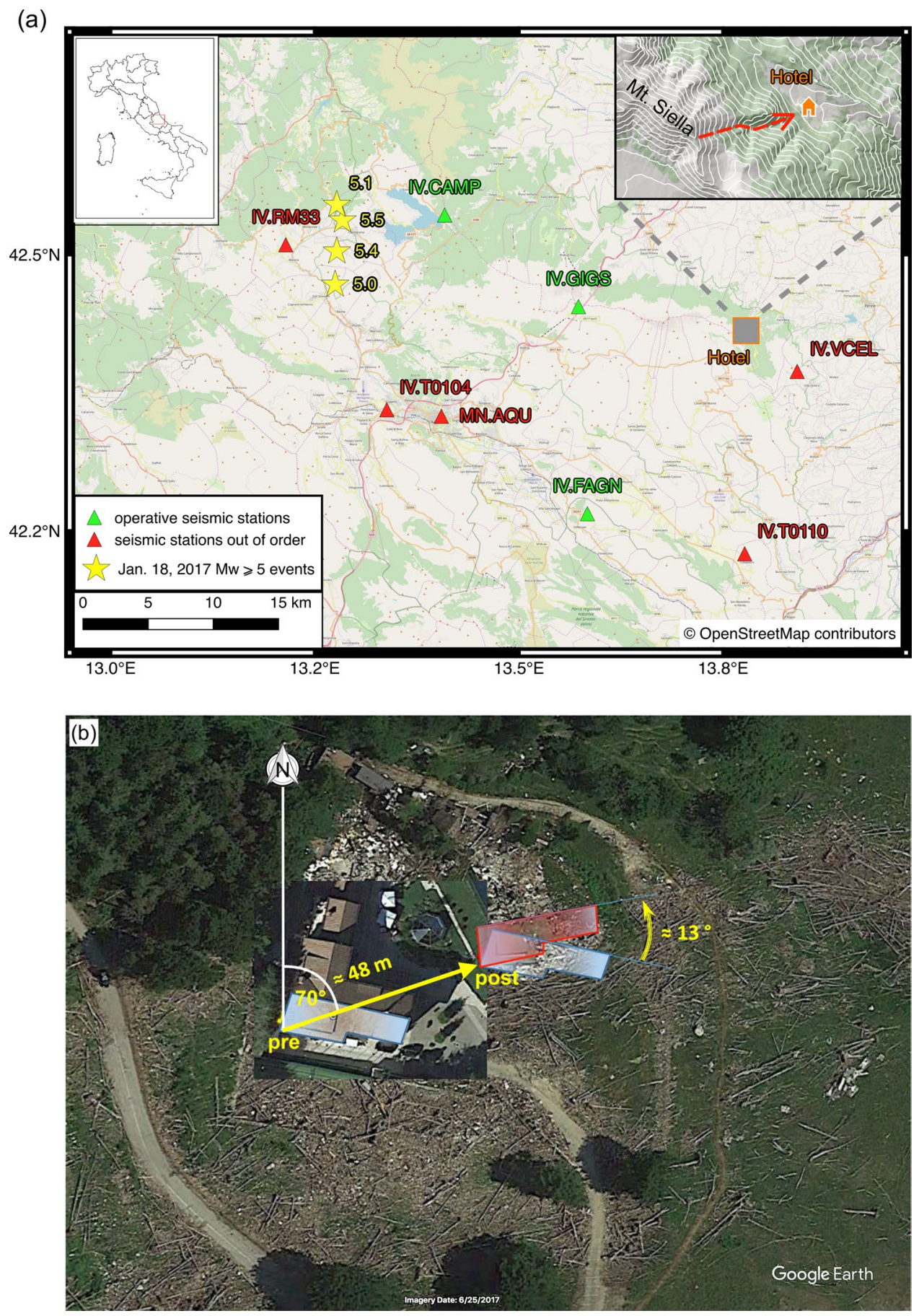

Figure 1. (a) Seismic stations of the INGV-network (triangles) installed in the Abruzzo area. The yellow stars indicate the earthquakes on January 18,2017 , which occurred at UTC 09:25:40 $\left(\mathrm{M}_{\mathrm{w}} 5.1\right), 10: 14: 09\left(\mathrm{M}_{\mathrm{w}} 5.5\right)$, 10:25:23 $\left(\mathrm{M}_{\mathrm{w}}\right.$ 5.4), and 13:33:36 $\left(\mathrm{M}_{\mathrm{w}}\right.$ 5.0). Only station GIGS, situated at $17 \mathrm{~km} \mathrm{~W}$ of Rigopiano, recorded a signal related to the avalanche that hit the hotel. (b) The avalanche caused a dislocation of the hotel's upper floor by $48 \mathrm{~m}$ in $\sim 70^{\circ} \mathrm{N}$ direction (measured by the dislocation from the SW-edge of the building from "pre" to "post") and a $\sim 13^{\circ}$ anticlockwise rotation. [This figure has been constructed using QGIS ${ }^{13}$, https://www.qgis.org/ en/site/; Map data copyrighted OpenStreetMap contributors; data is available under the Open Database License (https://www.openstreetmap.org/copyright), retrieved from https://planet.openstreetmap.org and Google Earth, imagery date 06/25/2017, https://www.earth.google.com]. 

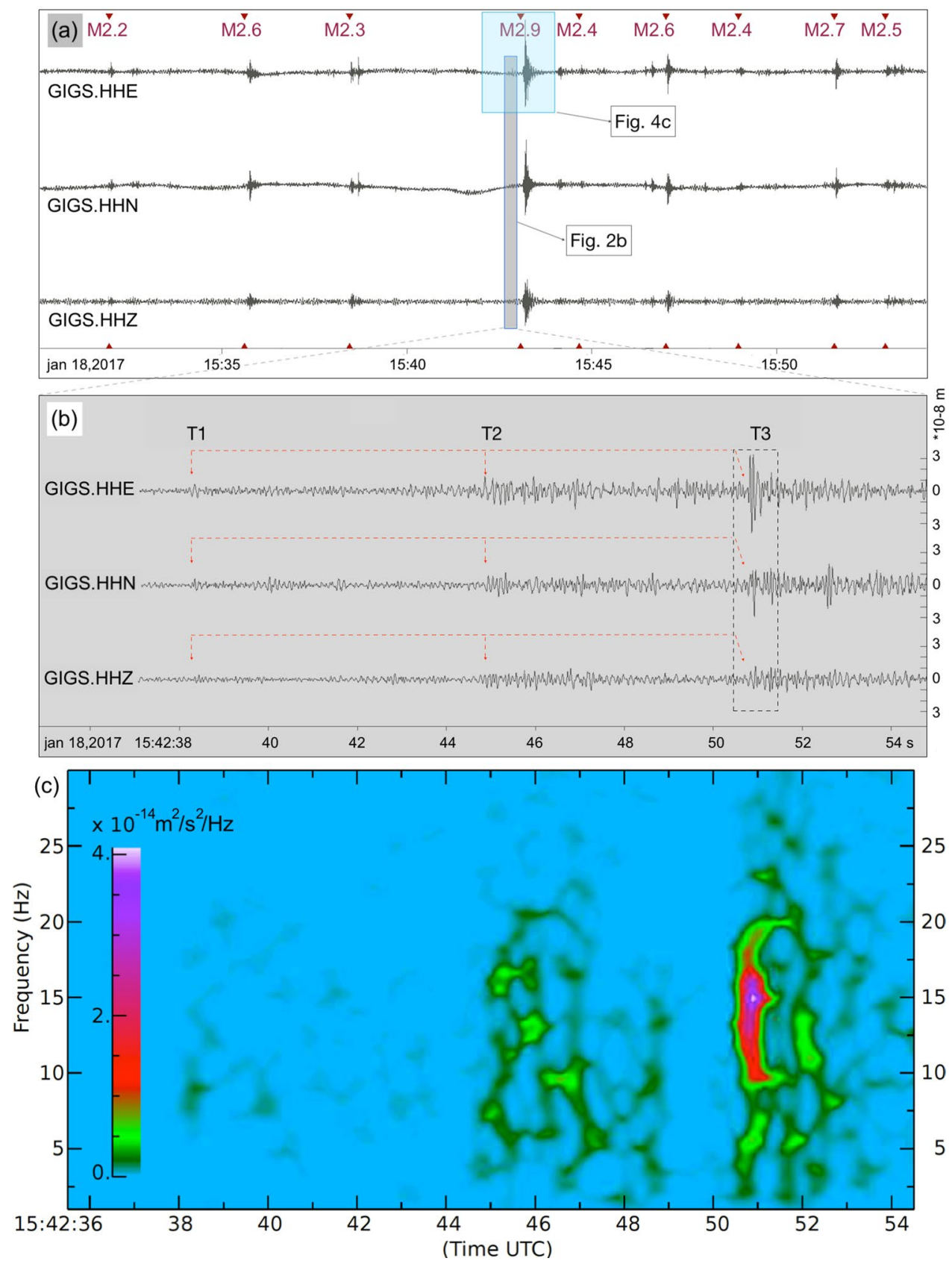

Figure 2. Seismic traces recorded at station GIGS: (a) $24 \mathrm{~min}$ zoom for the avalanche time window, (b) $20 \mathrm{~s}$ zoom, containing the displacement trace generated by the avalanche, (c) spectrogram of the E-component of station GIGS plotted for the $20 \mathrm{~s}$-time window of $(\mathbf{b})$, generated by the avalanche. [Panels a and $b$ have been plotted by using Snuffler, https://pyrocko.org; Panel c was realized using SAC-software: https://ds.iris.edu/ds/ nodes/dmc/forms/sac/].

Seismic data analyses. Due to the heavy snow falls in mid-January 2017, most of the-often solar-panelpowered-seismograph stations failed (red triangles in Fig. 1a). On January 18, 2017, only few seismic stations were running (green triangles in Fig. 1a); station GIGS was the closest operational station to hotel Rigopiano (distance of $17 \mathrm{~km}$ ). Prior to the data analyses, we verified the horizontal orientation of the three-component seismic broadband sensor of station GIGS (Nanometrics Trillium 240 s), installed inside the Gran Sasso Tunnel system and found a misalignment by $-36^{\circ} \mathrm{N}$ to be considered in the following analyses.

With the aim to determine the precise moment of the avalanche, we first inspect the seismograms of the nearest seismograph stations of the INGV-network (Fig. 1a). Figure 2a shows the eligible 24 min avalanche time window for all three components of station GIGS, which was scanned for any "suspicious" signal that could have been generated by the avalanche. The recordings are obviously dominated by the continuous seismic activity of the Central Italy sequence (inverted red triangles in Fig. 2a), which complicates the search. 
(a)

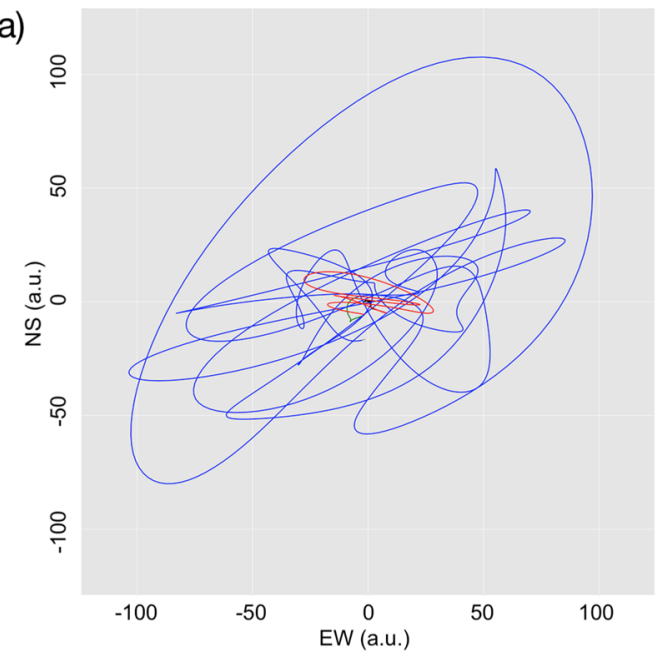

(c)

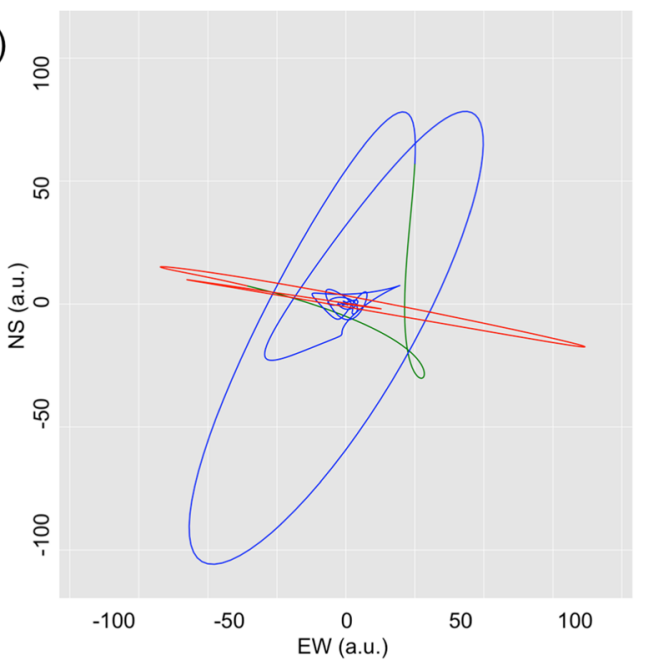

(b)

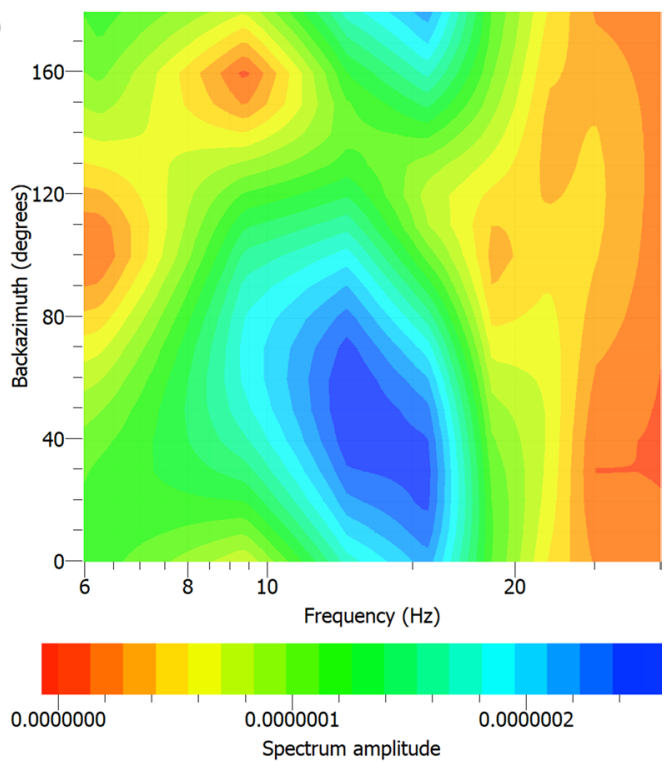

(d)

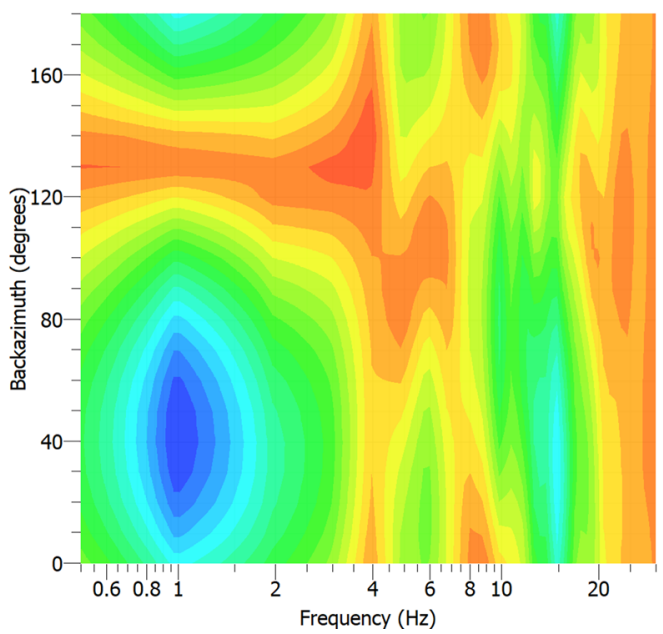

Figure 3. Directional analysis of the avalanche signal: (a) particle motion of the data and (c) of the synthetic seismograms (arbitrary units).Rotated frequency spectra calculated from combining the horizontal components of station GIGS for a time window of $(\mathbf{b}) 0.3 \mathrm{~s}$ and $(\mathbf{d}) 1.0 \mathrm{~s}$ around AT. [Panels $\mathrm{b}$ and $\mathrm{d}$ have been constructed by the software Geopsy, https://www.geopsy.org; Panels a and c have been realized using the software ObsPy https://github.com/obspy/obspy/wiki and SW4 ${ }^{20} \mathrm{https} / / /$ geodynamics.org//cig/software/github/sw4/v2.0/sw4v2.0.tgz].

At 15:42:38 the seismic trace of station GIGS started to record small transients on all three components, without any coincident signals at the other running stations of the network (triangles in Fig. 1a), which indicates that they had not been generated by the Central Italy seismic sequence. The signal has a duration of approximately $15 \mathrm{~s}$ and is composed by three distinct onsets (called hereafter avalanche transients T1-T3). T1 (1st red arrow in Fig. 2b) weakly starts at 15:42:38, followed by an amplitude increase $7 \mathrm{~s}$ later (T2-2nd red arrow) and culminating in the very sharp high-frequency $(\sim 14 \mathrm{~Hz})$ transient (T3-3rd arrow). T3 lasts for less than $0.5 \mathrm{~s}$ and is particularly evident on the horizontal-components, indicating an SH-wave. The peak ground velocity reaches a value of $3.2 \times 10^{-6} \mathrm{~m} / \mathrm{s}$, and a corresponding peak ground displacement of $3 \cdot 10^{-8} \mathrm{~m}$. The spectrogram in Fig. $2 \mathrm{c}$ shows the three distinct patterns as spectral energy in the frequency band of 1-20 Hz, with continuously increasing seismic energy at $38 \mathrm{~s}$ (T1), $45 \mathrm{~s}$ (T2) and $51 \mathrm{~s}$ (T3), respectively, the latter showing a distinct maximum at $\sim 14 \mathrm{~Hz}$ (violet).

In a second step, we try to determine the direction(s) under which the avalanche transients reach station GIGS, but only T3 shows a signal-to-noise ratio high enough to be further examined. Figure 3a shows the particle motion of T3 plotted in the horizontal NE-plane). The initial (red) part of the seismograms points approximately in direction $\sim 110^{\circ}$ (P-wave), while the large amplitudes (blue) show a mean direction of $\sim 45^{\circ}$ and can be interpreted as $\mathrm{SH}$-waves (T3).

To retrieve a statistically significant backazimuth of the short duration of $\mathrm{T} 3$, we compute the rotated frequency spectra of the horizontal components recorded at station GIGS, by calculating a series of Fourier spectra in the range from $0^{\circ}$ to $180^{\circ}$ (by steps of $10^{\circ}$ ) and present the outcome in the frequency-azimuth plane 
(Fig. 3b,d). Figure $3 \mathrm{~b}$ shows the rotated frequency spectra for the $0.3 \mathrm{~s}$ long time window around T3. The maximum spectral energy results at a frequency of $\sim 14 \mathrm{~Hz}$ and reaches station GIGS at a backazimuth of approximately $45^{\circ}$.

In a third step, we compute synthetic seismograms of the low frequency part of the T3 $(0.8-3 \mathrm{~Hz})$ and compare the corresponding particle motions with those of the band-pass filtered data $(0.8-3 \mathrm{~Hz})$ recorded at station GIGS (Fig. 3a). We use the software package $S W 4^{20}$, implementing a rough version of the true 3D topography (SRTM) and-according to the unidirectional movement of the avalanche-we assume as seismic source a shallow horizontally orientated single force (Gaussian shaped source time function in a frequency range of $0.8-3 \mathrm{~Hz}$ ). Based on a velocity model computed for estimating the regional moment tensors of the aftershock data from the 2009 L'Aquila earthquake sequence ${ }^{21}$, we calculate the synthetic seismograms for station GIGS by varying the single force direction in azimuthal steps of $10^{\circ}$. The result is that the synthetics (Fig. 3c) fit the particle motion of the observed data (Fig. 3a) best, when assuming a single force pointing in direction $120^{\circ} \mathrm{N}$. For the observed, as well as for the synthetic seismogram, both hodographs start with a linearly polarized P-phase, pointing to a backazimuth of $105^{\circ}-110^{\circ}$ for observed data (Fig. 3a) and in the $100^{\circ} \mathrm{N}$ direction for the synthetics (Fig. 3c), followed by an almost perpendicular polarized $\mathrm{SH}$-wave.

As the frequency bands of the recorded seismic data $(14 \mathrm{~Hz}$ for T3) and synthetic seismograms $(0.8-3 \mathrm{~Hz})$ differ substantially, the rotated frequency spectra have been repeated for an extended time window of $1 \mathrm{~s}$ around T3, revealing seismic energy around $1 \mathrm{~Hz}$, which arrives from the same backazimuth of $45^{\circ}$ as for the highfrequency (Fig. 3d).

Concluding, the 15 s-lasting seismic signal related to the avalanche, shows three distinct phases: at 15:42:38 (T1), $7 \mathrm{~s}$ later (T2), followed by the T3 another $6 \mathrm{~s}$ later. The SH-part of the T3 reaches station GIGS from $45^{\circ}$, which fits best to the particle motions of synthetic seismograms computed for a single force pointing in direction $120^{\circ} \mathrm{N}$.

Avalanche modelling. To better understand the dynamics of the Rigopiano avalanche, we simulated the event by using the extended version of Rapid Mass Movement Simulator (RAMMS ${ }^{22}$ ), able to compute a 2D simulation of the rapid movement's dynamics on a 3D alpine terrain. RAMMS is able to calculate a continuous numerical model of a mixed avalanche composed by a denser-but nevertheless fluidized-part (the core) and a nubiform part (powder snow) ${ }^{23}$. RAMMS considered further the process of the entrainment (snowpack erosion, variability of density, temperature and humidity of the snow in motion along the path) ${ }^{24}$ and allowed to calculate for the two-avalanche components pressure, velocity, density and flow height for each point of the running slope. The complexity of the avalanche dynamics saw the flow initially running on the non-wooded open slope, continuing on a partially incised slope strongly interacting with the forest, becoming almost a wood-and-snow mixed flow ${ }^{18,25}$. The simulation provided an estimation of the most probabilistic dynamics of the Rigopiano avalanche event of January 18, 2017. According to ${ }^{26}$, the main inputs of the simulation are:

- the released slab is characterized by an average thickness of $2 \mathrm{~m}$ with a density of $250 \mathrm{~kg} / \mathrm{m}^{3}$;

- the average inclination of the release area is $32^{\circ}$, from 1890 and 1760 m.a.s.l., with a total surface of about $38,500 \mathrm{~m}^{2}$, a released mass of $19,255 \mathrm{t}$ and volume of $77,000 \mathrm{~m}^{3}$

- the final avalanche density is assumed to increase to $450 \mathrm{~kg} / \mathrm{m}^{3}$ in the run-out area, resulting as an average between the typical value of snow in the avalanche flow plus incorporated wood of teared beeches.

Uncertainties in the avalanche calculations denote the variations from the average values of the initial parameters release height and slab density. In the fracture zone we employ an average release height of $\mathrm{h}=2 \mathrm{~m}$ assuming a possible variation of $\pm 0.5 \mathrm{~m}$. Concerning the average value of the fracture slab density $\rho$ we state: the snow density of fresh snow is lower than the average $\left(50 \mathrm{~kg} / \mathrm{m}^{3}<\rho<150 \mathrm{~kg} / \mathrm{m}^{3}\right)$, while the density of the older, settled snow is somewhat larger $\left(\rho>150 \mathrm{~kg} / \mathrm{m}^{3}\right)$. The average values $\left(\mathrm{h}=2 \mathrm{~m}\right.$ and $\left.\rho>250 \mathrm{~kg} / \mathrm{m}^{3}\right)$ therefore provide good estimates of the overall release volume, which is necessary to make computationally tractable and realistic simulations.

The avalanche simulation revealed that the avalanche developed in approximately $2 \mathrm{~min}$, reaching a high peak velocity of approximately $38 \mathrm{~m} / \mathrm{s}(\sim 136 \mathrm{~km} / \mathrm{h})$ along the track at about $1450 \mathrm{~m}$.a.s.l. The trajectory of the Rigopiano avalanche can be divided into two distinct zones (Fig. 4a): (i) the upper avalanche track from 1900 to 1500 m.a.s.l., with a mean slope angle of $30^{\circ}$ (against horizontal), is smooth, steep and free of trees. During its down-flow the avalanche accelerated and entrained fresh snow, entering a narrow canyon at 1500 m.a.s.l. (T1 in Fig. 4a), changing its channel width from 80 to $40 \mathrm{~m}$. The canyon shape causes the avalanche to change direction twice, each time being deflected by an angle of approximately $45^{\circ}$. After entering the canyon, the avalanche slows to a mean speed of $35 \mathrm{~m} / \mathrm{s}$ (Fig. 4a,b), reaching the first deflection point (T2) after $7 \mathrm{~s}$. Since the deflection points are separated by a distance of $250 \mathrm{~m}$ (T2 and T3 in Fig. 4a), we estimate the second impact (deflection) to occur at about $6 \mathrm{~s}$ after the first. At the deflection points, where the avalanche changes abruptly its flow direction, we expect large impact forces on the canyon sidewalls and therefore the generation of a significantly energetic seismic signal. It takes about $13 \mathrm{~s}$ for the avalanche front to navigate the canyon, the entire avalanche, including the tail, requires an additional $\sim 10 \mathrm{~s}$ to flow entirely through the narrow channel. The avalanche then departs the canyon, entering the lower, forested track segment, reaching the hotel after another $32 \mathrm{~s}$. This segment starts at an elevation of $1300 \mathrm{~m}$ and points towards the hotel. Topography constrains the avalanche to flow through a dense beech forest, carving a well-defined destructive corridor. After leaving the canyon, the simulation results show the avalanche flowing directly towards the hotel, stopping at the road (1080 m.a.s.l., Figs. 1b, 4a).

The flowing part (core) of the avalanche hit the hotel with a speed of about $28 \mathrm{~m} / \mathrm{s}(\approx 100 \mathrm{~km} / \mathrm{h})$ and at the simulation time of approximately $81 \mathrm{~s} \pm 5 \mathrm{~s}$, the maximum impact pressures reached $395 \mathrm{kPa}$ with an avalanche 


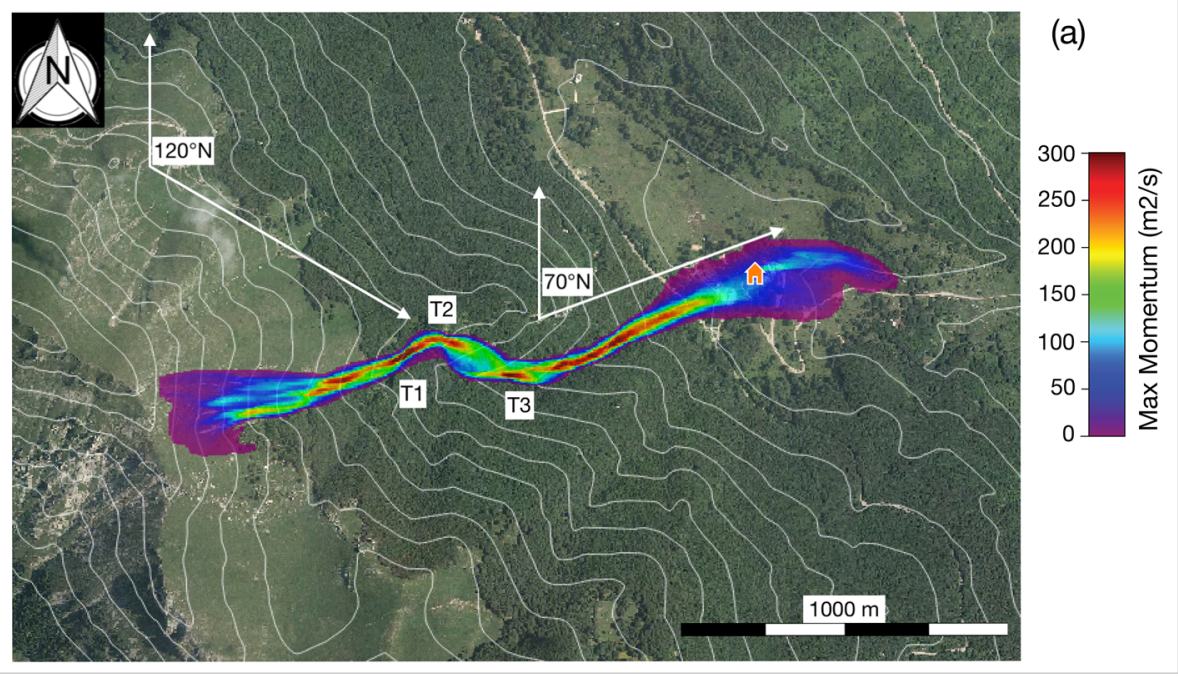

(b)

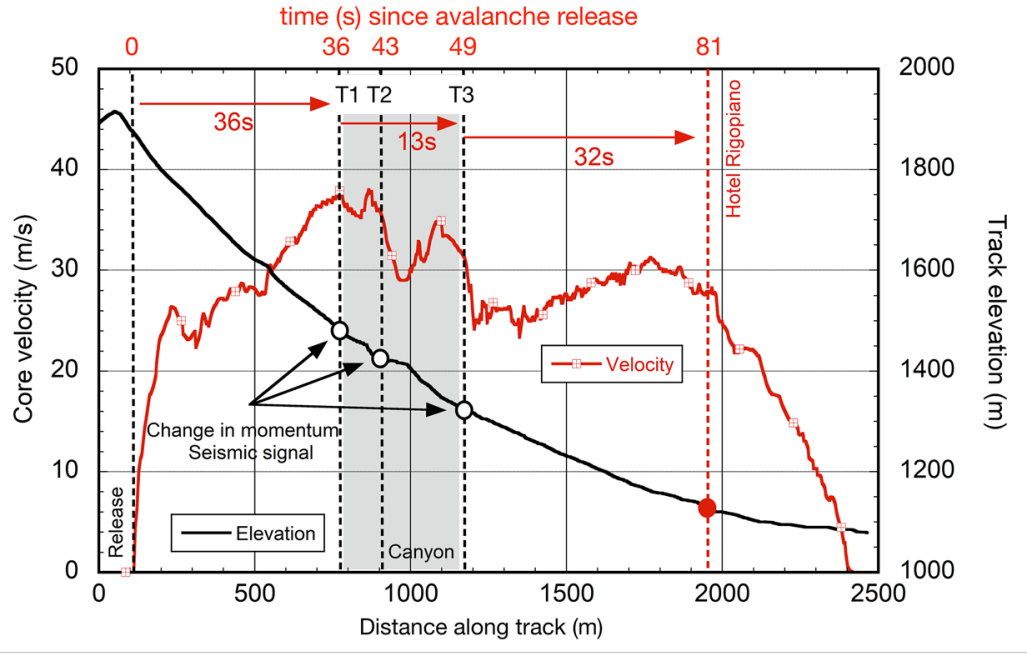

(c)

event time of avalanche (UTC)

Jan 18, 2017_15:41:59 15:42:35 $15: 42: 48 \quad 15: 43: 20$

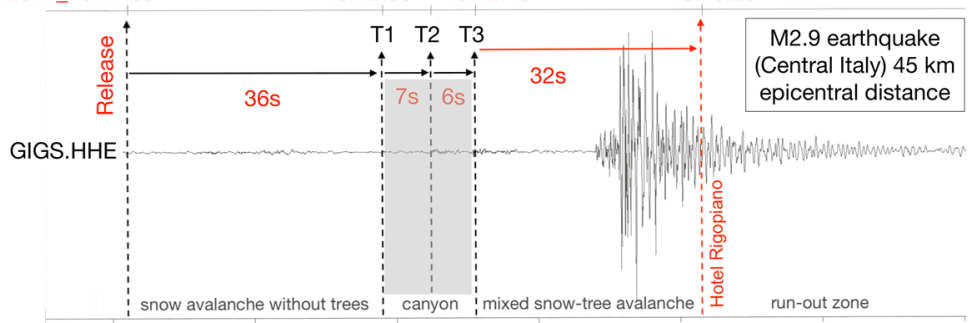

Jan 18, 2017_15:42:00

$15: 43: 00$

$15: 44: 00$

recording time at station GIGS (UTC), located at $17 \mathrm{~km}$ from Rigopiano (+3s travel time)

Figure 4. Track simulation of the Rigopiano avalanche of January 18, 2017, and comparison with the seismic signal: (a) progression of the modelled momentum along the avalanche track. At the entrance into the canyon (T1), and the deflection points (T2, T3) maximum momentum changes are expected. (b) Track elevation (black line), avalanche velocity (red line) and corresponding Time (s) after nucleation, as function of distance from the release area. (c) HHE-component of seismic recording (see Fig. 2a) indicating the onset times of the three avalanche transients (at 15:42:38, 45 and 51 UTC). The avalanche reaches the hotel after approximately $81 \mathrm{~s}$ inside the coda of a regional M2.9 event. [These figures have been realized using QGIS ${ }^{13}$, https://www.qgis.org/ en/site/, representing results of RAMMS ${ }^{22}$, plotted, together with $50 \mathrm{~m}$ contour lines, on "2013 AGEA digital orthophoto" available by Regione Abruzzo WMS service, https:/geoportale.regione.abruzzo.it/Cartanet/catal ogo/cartografia-di-sfondo-raster/ortofoto-digitale-agea-2013]. 
density of about $400 \mathrm{~kg} / \mathrm{m}^{3}$. After the initial peak (the arrival of the flowing front), a speed of $12 \mathrm{~m} / \mathrm{s}$ is hold up for further $15 \mathrm{~s}$ with a corresponding decrease of the avalanche body and its impact pressure from $395 \mathrm{kPa}$ to about $79 \mathrm{kPa}$. The avalanche entrained $103,000 \mathrm{~m}^{3}$ total volume of snow, obtaining a growth index of 2.3.

\section{Discussion and conclusions}

We investigated a 15 s-lasting seismic signal, recorded at station GIGS (located approximately $17 \mathrm{~km}$ away from the avalanche) that occurred at approximately the same time as the catastrophic event at Rigopiano and that cannot be associated to any earthquake of the Central Apennines seismic sequence. Besides, the significant time span between the four $M \geq 5$ events-which occurred between 09:25 and 13:33-and the snow avalanche event, makes the direct triggering effect unlikely.

On-site inspection clearly revealed that the avalanche caused a sudden horizontal shearing of the hotel building's second floor, which collapsed after accumulation of the snow masses along the external wall of the ground floor redirecting the avalanche to the second floor collapsing subsequently by shearing without affecting the foundation and thus without an efficient coupling into the ground.

The question is, whether shearing and dislocation of the hotel building's upper floor is capable to generate a seismic signal strong enough to be recorded by a seismic station located at a distance of $17 \mathrm{~km}$ ? We are convinced that the answer is "No".

To generate a seismic signal by an avalanche, a land slide or a rock fall, a strong force coupling between the mass flow and the ground is needed. Especially in the case of a snow avalanche, when the involved densities of the moving mass are relatively small, this coupling can arise either by the avalanche hammering onto the ground in the perpendicular direction of the flow, or when the avalanche impacts sidewalls, thus significantly changing its slope-parallel flow direction. As the slope-parallel velocities can reach $150 \mathrm{~km} / \mathrm{h}$, more seismic energy is generated by impacting sidewalls or buildings (obstacles). The main force of the avalanche is exerted downhill in the slope-parallel direction, while forces in the slope-perpendicular direction remain comparatively small. In fact, these forces are usually taken to be close to hydrostatic, and therefore depend on the height and density of the flowing snow. Sidewalls are thus ideal, because the large slope-parallel momentum of the avalanche is transferred directly into ground. When an avalanche flows on a smooth slope (without obstacles) almost no seismic energy couples to the ground, requiring seismic sensors to be installed in the near vicinity to measure any potential avalanche induced ground shaking.

Concluding, a significant seismic signal generated during the impact of the avalanche with a building can only be generated if the building can withstand the avalanche forces, transferring the momentum of the impact directly to the foundation sub-structure and then to the ground.

At Rigopiano the huge avalanche volume of $77,000 \mathrm{~m}^{3}$ is characterized by low mean densities of $250 \mathrm{~kg} / \mathrm{m}^{3}$ (in the release zone and the forest-free upper part), increasing up to $450 \mathrm{~kg} / \mathrm{m}^{3}$ (inside the mixed wood-andsnow avalanche that reaches the run out area), summing up to a total mass of 19,255 t. Rockfalls or landslides of similar volumes are characterized by much higher density values (factor 5-10), such that the normal force exerted couples seismic energy into the ground, generating the typical long-lasting seismic signal during the downhill movement ${ }^{1,3,4}$.

The seismic recordings show three distinct "avalanche transients" (T1,T2,T3 in Fig. 2b), which synchronize well with the main momentum changes revealed by the avalanche simulation (T1, T2, T3 in Fig. 4). We believe that the seismic signal is related to the change in momentum (avalanche height $x$ avalanche velocity, Fig. 4a). Considering that on its way downwards, the avalanche mass increases continuously, the momentum of the moving mass flow changes significantly when its velocity changes due to narrowing of the flow channel (canyon) or deflection $^{9,10}$. The bigger the change, the bigger the force.

This is confirmed by the directional analysis. The particle motion of the avalanche transient with the highest amplitude (T3) reveal a P-phase pointing away from GIGS in direction $105^{\circ}-110^{\circ} \mathrm{N}$, followed by an $\mathrm{SH}$-wave in NE-SW direction. According to the kind of movement of an avalanche flow along a surface, we assume single forces as seismic sources. To reproduce the hodograph of the seismic signal recorded at station GIGS, we calculate synthetic seismograms for a single force varying the attack angle in steps of $10^{\circ}$. The corresponding particle motion diagrams of the synthetics fit the data best for the single force in direction of $120^{\circ} \mathrm{N}\left(\mathrm{SF} 120^{\circ} \mathrm{N}\right.$ in Fig. 4a) concordant to the impact direction of the avalanche on the sidewalls of the canyon, rather than for $70^{\circ} \mathrm{N}$ $\left(\mathrm{SF} 70^{\circ} \mathrm{N}\right.$ in Fig. $\left.4 \mathrm{a}\right)$ the direction the avalanche hits the hotel building. The seismic trace and the corresponding spectrogram (Fig. 2c) reveal two distinct earlier phases (at 15:42:38 s and $45 \mathrm{~s}$ ) before the T3 (at $51 \mathrm{~s}$ ). These phases show a similar spectral energy pattern as T3 and are temporally separated by two time intervals of 6-7 s, which are also found by the avalanche simulation passing through the canyon.

While GPS-timing of the seismic recordings and avalanche parameters retrieved from on-site inspections can be considered as "precise", some words have to be said about uncertainties of the calculated and modeled parameters.

The horizontal orientation of the seismometer inside the Gran Sasso Tunnel was checked by a Fibre Optic Gyrocompass and revealed a misalignment of $-36^{\circ}$, which are thence considered in all calculations. We estimate the backazimuths uncertainties of the GIGS-traces as at least $10^{\circ}$, five times higher than the $2^{\circ}$ aperture angle between the release area and the run-out zone of the avalanche (with respect to GIGS). In our argumentation the backazimuths of the seismic avalanche transients prove that the corresponding seismic source is located ESE of GIGS, and not in the north-west direction, as for the epicentres of the concomitant seismic sequence in the Central Apennines (Fig. 1a). Accordingly, also synthetic seismograms are calculated for single force pointing in direction in steps of $10^{\circ}$, which is precise enough to distinguish between the two single force directions of $70^{\circ} \mathrm{N}$ and $120^{\circ} \mathrm{N}$, in favour of the latter solution. 
Hundreds of avalanche models have been calculated, varying snowpack erosion, density, temperature and humidity of the snow in motion along the path. All simulations result in slightly different final values for pressure, mass, density, snow pack height and velocity. The only simulation parameters relevant for confirming the seismic signature of the Rigopiano avalanche, are, however, the momentum changes and the associated travel times, at the moment the avalanche passes the canyon (T1, T2, T3, Fig. 4). As the topography of the avalanche track is well known, it can be stated that the uncertainties of the relative travel times-when passing the short and narrow canyon (T1, T2, T3, in Fig. 4) - do not exceed \pm 0.5 s, respectively.

Coming back to the question about the exact timing we compare the variation of the simulated track elevation and avalanche velocity (Fig. 4b) with the temporal evolution of the avalanche recorded by the seismogram (Fig. 4c). As the seismic recordings of events occurring at Rigopiano take about $3 \mathrm{~s}$ travel time to reach station GIGS $17 \mathrm{~km}$ away, Fig. 4c indicates two different time scales: in red, the Time (UTC) shifted by the travel time correction of $3 \mathrm{~s}$ and in black, the UTC-timing for the seismogram.

- $15: 41: 59 \pm 2.5 \mathrm{~s}$ : avalanche release

- 15:42:35 $\pm 0.5 \mathrm{~s}$ : T1 is generated once the avalanche enters the canyon

- $15: 42: 42 \pm 0.5 \mathrm{~s}:$ T2 first deflection

- 15:42:48 $\pm 0.5 \mathrm{~s}: \mathrm{T} 3$ second deflection

- $15: 43: 20 \pm 5.0 \mathrm{~s}$ : the avalanche reaches the hotel.

The large uncertainty in the definition of the release time $( \pm 2.5 \mathrm{~s})$ is associated with the break-up of the fracture slab into smaller fragments. This process determines the transition from the motion of a solid block to a granular fluid and therefore the initial speed of the avalanche. Once the granularization process is complete, the uncertainties in the model calculations decrease significantly to $\pm 1.0 \mathrm{~s}$.

We calculated that the theoretical onset time of a hypothetical seismic signal caused by the impact of the avalanche with the hotel, has to be expected at $\sim 81 \mathrm{~s} \pm 5 \mathrm{~s}$ after the avalanche release. This instant falls exactly in the eligible time window when station GIGS recorded a M2.9 earthquake from the Central Italy seismic sequence, thus masking in its S-wave coda any hypothetical signal caused by the detachment of the hotel's upper floor due to the avalanche (see Fig. $4 \mathrm{c}$ ).

Between January 15 and 18, 2017, the cumulated height of fresh snow in 3 days at an altitude of $1880 \mathrm{~m}$ a.s.l. was close to $360 \mathrm{~cm}$ (without counting local snowdrift effects). The rising temperatures ${ }^{27}$ above $0{ }^{\circ} \mathrm{C}$ in the course of the day in combination with the growing snowpack may have contributed more significantly to the destabilization of the snow slope, leading to the stress causing the energetic triggering of the deadly avalanche ${ }^{28,29}$. As a matter of fact, between January 15 and 18, more than 520 large or very large avalanche events occurred in that area of the Italian Central Apennines ${ }^{30}$.

\section{Data availability}

The dataset generated during and/or analyzed during the current study are available from the corresponding author on request.

Received: 29 January 2019; Accepted: 13 October 2020

Published online: 29 October 2020

\section{References}

1. Hibert, C., Stark, C. P. \& Ekström, G. Dynamics of the Oso-Steelhead landslide from broadband seismic analysis. Nat. Hazards Earth Syst. Sci. 15, 1265-1273. https://doi.org/10.5194/nhess-15-1265-2015 (2015).

2. Hasegawa, H. \& Kanamori, H. Source mechanism of the magnitude 72 Grand Banks earthquake of November 1929: Double couple or submarine landslide?. Bull. Seismol. Soc. Am. 77, 1984-2004 (1987)

3. Brodsky, E. E., Gordeev, E. \& Kanamori, H. Landslide basal friction as measured by seismic waves. Geophys. Res. Lett. https://doi. org/10.1029/2003GL018485 (2003).

4. Pino, N. A., Ripepe, M. \& Cimini, G. B. The Stromboli volcano landslides of December 2002: A seismological description. Geophys. Res. Lett. https://doi.org/10.1029/2003GL018385 (2004).

5. Johnson, J. B. \& Ronan, T. J. Infrasound from volcanic rockfalls. J. Geophys. Res. Solid Earth 120, 8223-8239. https://doi. org/10.1002/2015JB012436 (2015).

6. Suriñach, E. et al. Seismic detection and characterization of landslides and other mass movements. Nat. Hazards Earth Syst. Sci. 5, 791-798. https://doi.org/10.5194/nhess-5-791-2005 (2005).

7. Suriñach, E., Sabot, F., Furdada, G. \& Vilaplana, J. M. Study of seismic signals of artificially released snow avalanches for monitoring purposes. Phys. Chem. Earth 25, 721-727 (2000).

8. Surinach, E., Furdada, G., Sabot, F., Biescas, B. \& Vilaplana, J. On the characterization of seismic signals generated by snow avalanches for monitoring purposes. Ann. Glaciol. 32, 268-274 (2001).

9. Vilajosana, I., Suriñach, E., Khazaradze, G. \& Gauer, P. Snow avalanche energy estimation from seismic signal analysis. Cold Reg. Sci. Technol. 50, 72-85 (2007).

10. Vilajosana, I., Khazaradze, G., Suriñach, E., Lied, E. \& Kristensen, K. Snow avalanche speed determination using seismic methods. Cold Reg. Sci. Technol. 68, 1521-1530 (2007).

11. Cat Berro, D. 15-19 Gennaio 2017:Tempesta di Bora e nevicate straordinarie sul versante adriatico. https://www.nimbus.it/event i/2017/170123NeveItalia.htm (2017).

12. Geggel, L. Earthquakes or Snowstorms? Cause of Italy's Deadly Avalanche Debated. https://www.livescience.com/57563-did-earth quakes-cause-italy-avalanche.html (2017).

13. QGIS. QGIS Geographic Information System, Open Source Geospatial Foundation. https://qgis.org/en/site/ (2009).

14. Repubblica. Il sopravvissuto di Rigopiano. https://www.repubblica.it/cronaca/2017/02/12/news/il_sopravvissuto_di_rigopiano_ sono_uscito_un_istante_e_ho_visto_l_inferno_mi_chiamano_eroe_ma_ho_paura_del_buio_-158113059/(2017).

15. TGcom24. Rigopiano, i testimoni dall'hotel. https://www.tgcom24.mediaset.it/cronaca/rigopiano-i-testimoni-dall-hotel-ho-visto -la-montagna-cadere-_3052137-201702a.shtml (2017). 
16. BBC. Rigopiano Hotel Avalanche: Italian Rescuers Find No Sign of Life. https://www.bbc.com/news/world-europe-38674788 (2017).

17. Repubblica. Rigopiano un mese dopo: perché la tragedia si poteva evitare. https://www.repubblica.it/cronaca/2017/02/14/news/ valanga_su_rigopiano_un_mese_dopo-158276130/(2017).

18. Feistl, T. et al. Observations and modeling of the braking effect of forests on small and medium avalanches. J. Glaciol. 60, 124-138. https://doi.org/10.3189/2014JoG13J055 (2014).

19. Bartelt, P. \& Stoeckli, P. The influence of tree and branch fracture, overturning and debris on snow avalanche flow. Ann. Glaciol. 32, 209-216 (2001).

20. Petersson, N. A. \& Sjögreen, B. SW4 v1.1. https://geodynamics.org/cig/software/sw4/ (2014).

21. Herrmann, R. B., Malagnini, L. \& Munafò, I. Regional moment tensors of the 2009 L'Aquila earthquake sequence. Bull. Seismol. Soc. Am. https://doi.org/10.1785/0120100184 (2011).

22. WSL-SLF. RAMMS-Rapid Mass Movement Simulator. https://ramms.slf.ch/ramms/ (2018).

23. Bartelt, P., Buser, O., Valero, C. V. \& Bühler, Y. Configurational energy and the formation of mixed flowing/powder snow and ice avalanches. Ann. Glaciol. 57, 179-188. https://doi.org/10.3189/2016AoG71A464 (2016).

24. Bartelt, P., Christen, M., Bühler, Y., Caviezel, A. \& Buser, O. Snow entrainment: avalanche interaction with an erodible substrate. In Proceedings of the International Snow Science Workshop, 716-720.

25. Teich, M. et al. Computational snow avalanche simulation in forested terrain. Nat. Hazard Earth Syst. Sci. 14, 2233-2248. https:// doi.org/10.5194/nhess-14-2233-2014 (2014).

26. Frigo, B. et al. The January 18th 2017 Rigopiano avalanche disaster in Italy - Analysis of the avalanche dynamics. In Proceedings of the International Snow Science Workshop, 7-12 October 2018, Innsbruck, Austria, 6-10 (2018).

27. McClung, D. M. \& Schweizer, J. Skier triggering, snow temperatures and the stability index for dry slab avalanche initiation. J. Glaciol. 45, 190-200. https://doi.org/10.1017/S0022143000001696 (1999).

28. Chiaia, B., Cornetti, P. \& Frigo, B. Triggering of dry snow slab avalanches and active protection. Cold Reg. Sci. Technol. 53, 170-178 (2008).

29. Reuter, B. \& Schweizer, J. Describing snow instability by failure initiation, crack propagation, and slab tensile support. Geophys. Res. Lett. 45, 7019-7027. https://doi.org/10.1029/2018GL078069 (2018).

30. Chiambretti, I. \& Sofia, S. Winter 2016-2017 snowfall and avalanche emergency management in Italy (Central Apennines) - A review. In Proceedings of the International Snow Science Workshop, 7-12 October 2018, Innsbruck, Austria, 1445-1449 (2018).

\section{Acknowledgements}

One of the co-authors (D.F.) was financed by DPC grant (INGV-DPC B2 2017 OB1 Task B) n 0304-022. Map data copyrighted OpenStreetMap contributors; data is available under the Open Database License (https://www. openstreetmap.org/copyright), retrieved from https://planet.openstreetmap.org.

\section{Author contributions}

T.B. and D.F., conducted the seismic data analyses and created Figs. 1a, 2, 3b,d, 4c. J.W., measured the installation orientation of GIGS-sensor by using a FOG, calculated the synthetic seismograms and prepared Fig. 3a,c. P.B., computed the avalanche simulation, creating Fig. 4a,b. B.F. and B.C., performed the avalanche site inspection and the structural analysis and prepared Fig. 1b. T.B., B.F., and P.B., discussed the results and wrote the main text. All authors reviewed the manuscript.

\section{Competing interests}

The authors declare no competing interests.

\section{Additional information}

Correspondence and requests for materials should be addressed to T.B.

Reprints and permissions information is available at www.nature.com/reprints.

Publisher's note Springer Nature remains neutral with regard to jurisdictional claims in published maps and institutional affiliations.

(c) (i) Open Access This article is licensed under a Creative Commons Attribution 4.0 International License, which permits use, sharing, adaptation, distribution and reproduction in any medium or format, as long as you give appropriate credit to the original author(s) and the source, provide a link to the Creative Commons licence, and indicate if changes were made. The images or other third party material in this article are included in the article's Creative Commons licence, unless indicated otherwise in a credit line to the material. If material is not included in the article's Creative Commons licence and your intended use is not permitted by statutory regulation or exceeds the permitted use, you will need to obtain permission directly from the copyright holder. To view a copy of this licence, visit http://creativecommons.org/licenses/by/4.0/.

(C) The Author(s) 2020 